\title{
EFFECT OF CHILLING STRESS ON THE PHOTOSYNTHETIC PERFORMANCE OF YOUNG PLANTS FROM TWO MAIZE (ZEA MAYS) HYBRIDS
}

\author{
Rositsa Cholakova-Bimbalova, ${ }^{1}$ Andon Vassilev ${ }^{2}$
}

\begin{abstract}
In the climate conditions of Bulgaria, early stages of maize plants development often go under suboptimal temperatures. Chilling stress is known to cause different physiological disturbances in young maize plants during the transition period from heterotrophic to autotrophic nutrition. However, the effect of chilling may differ among maize hybrids. Photosynthetic performance could be a good indicator for the hybrid tolerance to chilling. The aim of our study was to evaluate the tolerance of young maize plants from two hybrids - the new Bulgarian hybrid - Kneza 307 and the hybrid P9528 using as criteria the changes in their photosynthetic performance.

Plants at the third leaf stage were exposed for seven days to chilling stress. At the end of the experimental period, growth, leaf lipid peroxidation, and several photosynthetic parameters were measured. We found that chilling stress reduced the fresh mass accumulation, increased lipid peroxidation, diminished net photosynthetic rate and chlorophyll content, and enhanced non-photochemical quenching of chlorophyll fluorescence. Although the responses of both hybrids were similar, some specificity were observed and discussed.
\end{abstract}

UDC Classification: 581.1; DOI: http://dx.doi.org/10.12955/cbup.v5.1081

Keywords: Zea mays, chilling, photosynthesis, pigments, chlorophyll fluorescence

\section{Introduction}

Maize (Zea mays) is a tropical crop which has a relatively high temperature optimum for growth and development: $30-35{ }^{\circ} \mathrm{C}$ (Miedema, 1982). Temperatures below $12-15^{\circ} \mathrm{C}$ may damage the young plants, causing chilling stress (Hola et al., 2007; Leipner, 2009). Maize plants are the most sensitive to chilling during the transitional phase from heterotrophic to autotrophic nutrition (Stamp, 1984), which usually lasts several weeks after sowing. In the climate conditions of Bulgaria, maize plants during their early stages of development are often subjected to suboptimal temperatures. Chilling provokes different physiological disorders in maize plants. It disturbs the balance between formation and quenching of the reactive oxygen species (Foyer et al., 2002), damages membrane integrity (Aroca et al., 2003) and modulates enzyme activities (Farooq et al., 2008; Takac, 2004). These negative effects are further multiplied on the scale of cardinal physiological processes, such as mineral nutrition, water relations, photosynthesis, dark respiration, etc. and lead to plant growth inhibition (Leipner, 2009; Zaidi et al., 2010).

Photosynthesis is one of the processes most susceptible to low-temperature inhibition in maize (Zea mays) (Nie et al., 1992). Chilling stress negatively affects both formation and functional activity of the photosynthetic apparatus of the plants (Leipner, 2009; Sowinski et al., 2005). It has been shown that it decreases stomata conductance (Aroca et al., 2001; Melkonian et al., 2004), disturbs chloroplast development (Moseki, 2004; Nie et al., 1995), diminishes photosynthetic pigment content (Haldimann, 1998, 1999) and lowers PSII photochemistry and $\mathrm{CO}_{2}$ assimilation (Al-Shoaibi, 2008; Bilska and Sowinski, 2010). It also retards photosynthate transfer to the phloem and photosynthate export from the leaves (Bilska and Sowinski, 2010).

The performance of maize plants during both chilling stress and recovery strongly depends on hybrid tolerance (Bano et al., 2015; Sowinski et al., 2005). Many reports demonstrated significant differences in chilling tolerance among maize hybrids (Aroca et al., 2001, 2003; Haldimann 1998, 1999; Hola et al., 2007). Photosynthetic performance during the chilling period and after recovery could be a good indicator for the hybrid tolerance to chilling. In fact, many authors studied maize hybrids' tolerance to chilling temperature using photosynthetic parameters as criteria (Haldimann, 1998; Kosova et al., 2005; Sowinski et al., 2005).

The tolerance of Bulgarian maize hybrids to chilling stress is not well characterized. Therefore, we decided to perform a study aiming to evaluate the tolerance of young maize plants from two hybrids, using as criteria the changes in their photosynthetic performance.

\footnotetext{
${ }^{1}$ Agricultural University of Plovdiv, Plovdiv, Bulgaria, rositsa.cho@abv.bg

${ }^{2}$ Agricultural University of Plovdiv, Plovdiv, Bulgaria, vassilev@au-plovdiv.bg
} 


\section{Material and methods}

The experiments were carried out in a climatic room of the Department of Plant Physiology and Biochemistry at the Agricultural University of Plovdiv, Bulgaria. Maize plants from two hybrids: Kneza 307 (Kn.307) and P9528, were grown as a hydroponic culture on $1 / 2$ strength modified Hoagland nutrient solution at controlled environment: photoperiod - 12 hours, PPFD (photosynthetic photon flux density) $200 \mu \mathrm{mol} \mathrm{m} \mathrm{m}^{-2} \mathrm{~s}^{-1}$, temperature $-25 \pm 1^{\circ} \mathrm{C} / 20 \pm 1^{\circ} \mathrm{C}$ (day/night) and relative air humidity $-60 \pm 5 \%$. The solution was aerated 15 minutes per hour.

At the appearance of the $3^{\text {-rd }}$ leaf of maize plants, the following experimental design was arranged. Plants from both hybrids were cultivated for the next seven days at different temperature regimes, namely: no chilling regime $25 \pm 1^{\circ} \mathrm{C} / 20 \pm 1^{\circ} \mathrm{C}$ (day/night) and chilling regime $10 \pm 1^{\circ} \mathrm{C}$ - constantly. Each treatment consisted of 3 replications (pots) with four plants per pot. The experiment was performed twice.

Both growth and photosynthetic performance of the maize plants were analyzed at the end of the experiments. Leaf gas exchange (A - net photosynthetic rate, $\mathrm{E}$ - transpiration rate, $\mathrm{g}_{\mathrm{s}}$ - stomatal conductance as well as $\mathrm{c}_{\mathrm{i}}$ - internal $\mathrm{CO}_{2}$ concentration) was measured by an open photosynthetic system LCpro+ (ADC, England) on the upper fully developed leaf, at PPFD of $450 \mu \mathrm{mol} \mathrm{m}^{-2} \mathrm{~s}^{-1}$, after one hour adaptation.

Chlorophyll fluorescence measurements were performed with a pulse modulation fluorometer (MINIPAM, Heinz Walz, Germany) in the same leaves after dark and light adaptation. The measurements were done on both top-leaf zone and middle-low part zone of the leaf lamina in no chilled and chilled plants. The maize plants were kept in the dark for $30 \mathrm{~min}$ before the start of the measurement. By switching on the measuring beam $(0.02-0.20 \mu \mathrm{mol} \mathrm{m}-2 \mathrm{~s}-1)$, the minimal level of fluorescence (F0) was recorded. Immediately after that, a saturating light pulse of $5500 \mu \mathrm{mol} \mathrm{m}-2 \mathrm{~s}-1$ with $0.8 \mathrm{~s}$ duration was sent out to record the maximal level of fluorescence in the dark-adapted state (Fm), from which the maximal quantum yield of PSII (Fv/Fm) was calculated (with Fv = Fm - F0). After 30 min light adaptation at $450 \mu \mathrm{mol} \mathrm{m}-2 \mathrm{~s}-1$ the steady-state level of photosynthesis was achieved, and a saturating pulse with the same characteristics was applied. Fluorescence yields before triggering the saturation pulse $(\mathrm{F})$; maximal $(\mathrm{Fm}$ ') fluorescence, reached during the saturation pulse; as well as an apparent electron transport rate ETR as (Genty et al., 1989),

(1) $\mathrm{ETR}=\mathrm{Y} \times \mathrm{PAR} \times 0.5 \times 0.84$, where $\mathrm{Y}=(\mathrm{Fm} '-\mathrm{F}) / \mathrm{Fm}$ '.

Both photochemical quenching $\mathrm{qP}$ and non-photochemical quenching $\mathrm{qN}$, can be calculated according to Schreiber (2004).

(2) $\mathrm{qP}=\left(\mathrm{Fm} \mathrm{m}^{\prime}-\mathrm{F}\right) /\left(\mathrm{Fm}{ }^{\prime}-\mathrm{F} 0\right)$

(3) $\mathrm{qN}=\left(\mathrm{Fm}-\mathrm{Fm}{ }^{\prime}\right) /(\mathrm{Fm}-\mathrm{F} 0)$,

Photosynthetic pigments (chlorophyll a, chlorophyll $\mathrm{b}$ and total carotenoids) were extracted in $80 \%$ acetone, measured spectrophotometrically and calculated according to the formulae of Lichtenthaler (1987).

For the measurement of lipid peroxidation in leaves, the thiobarbituric acid (TBA) test, which determines malonyldialdehyde (MDA) as an end product of lipid peroxidation (Heath and Parker, 1968), was used. The amount of MDA-TBA complex (red pigment) was calculated from the extinction coefficient $155 \mathrm{mM}^{-1} \mathrm{~cm}^{-1}$. Plant fresh weight was determined at the end of the experiments.

Statistical analysis was performed using one-way ANOVA (for $\mathrm{P}<0.05$ ). Based on ANOVA results, a Duncan test for mean comparison was conducted, for a 95\% confidence level, to test for significant differences among treatments. In the figure and the tables, different letters (a, b, c and d) express significant differences at the $\mathrm{P}<0.05$.

\section{Results and discussion}

The applied seven-day-long chilling significantly retarded the plant growth of both maize hybrids (Figure 1). The fresh weight of the chilled plants from Kn.307 and P9528 were lower as compared with the plants grown at the $25 / 20^{\circ} \mathrm{C}$ regime by $67 \%$ and $68 \%$, respectively. In addition to the inhibited growth, the chilled plants were distinguished by some leaf yellowing, in particular between 
the middle and the lower part of the lamina of the $3^{\text {-rd }}$ leaf. These symptoms were more expressed in the leaves of the hybrids Kn.307.

The data concerning MDA content, which is a marker for oxidative degradation of membrane lipids, is also presented in Figure 1. The results show that the MDA content significantly increased in the chilled plants - $39 \%$ in hybrid Kn.307 and 24\% in hybrid P9528. The higher lipid degradation in the leaves of these plants provides evidence they suffered from chilling-provoked oxidative stress. The upper leaf MDA content in the chilled plants from the hybrid Kn.307, the more expressed damage symptoms as well as, the more strongly depressed growth as compared with that of P9528, show this hybrid is more susceptible to such conditions.

Figure 1: Influence of chilling on plant fresh weight $\left(\mathrm{FW} ; \mathrm{g}\right.$ plant $\left.{ }^{-1}\right)$ and malondialdehyde content (MDA; nmol $\mathrm{g}^{-1} \mathrm{FW}$ ) in the leaves of young maize hybrids Kn.307 and P9528.

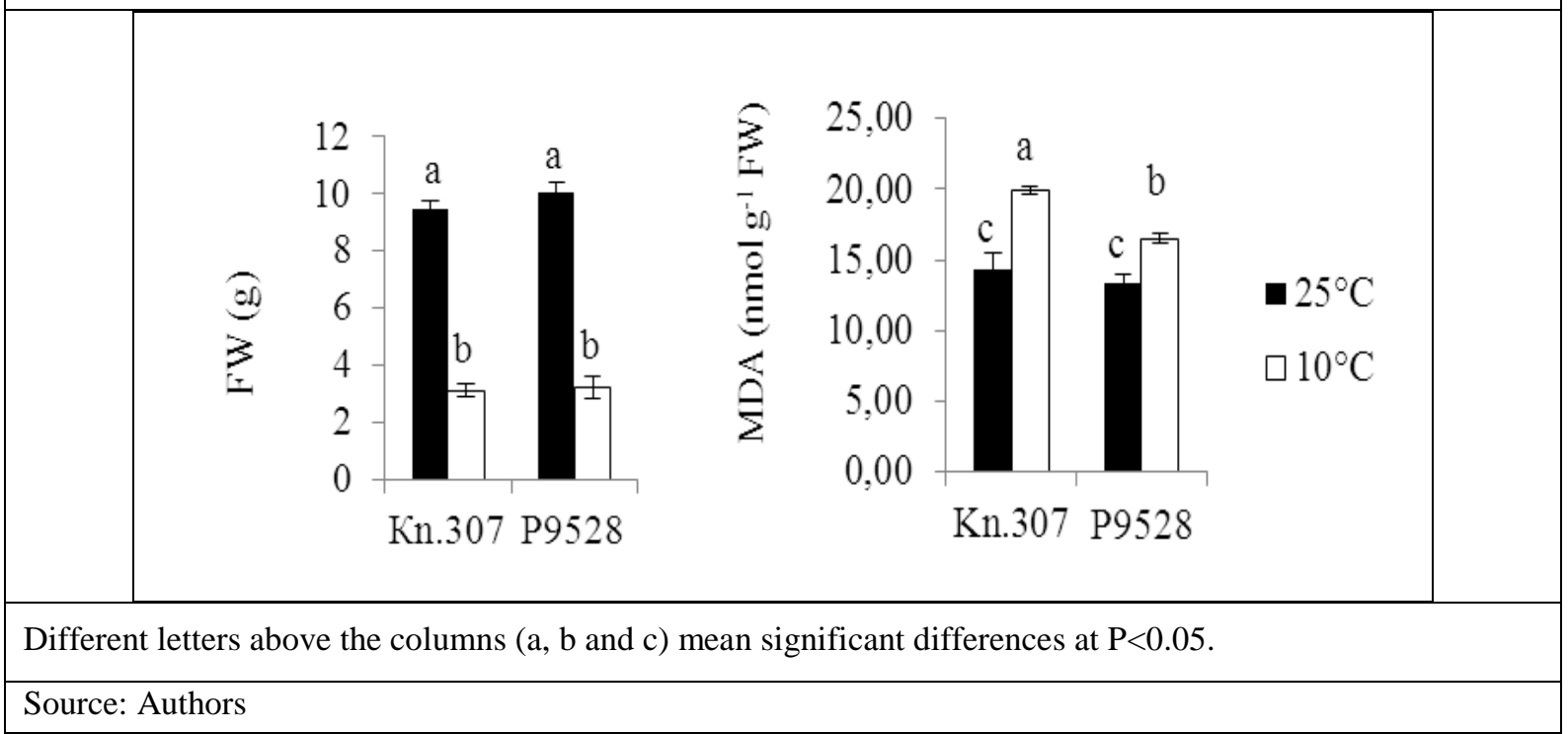

The data presented in Table 1 shows the effect of chilling on leaf gas exchange of maize plants. The net photosynthetic rate (A) of both maize hybrids, grown at no chilling regime, was similar, while a larger difference was observed between the respective values of the chilled plants. The chillinginduced decrease of A was 67\% in Kn.307 and much less - 44\% in P9528. Our results well correspond well with Al-Shoaibi's (2008) observation for strongly retarded carboxylation efficiency of chillingexposed maize plants.

The chilling significantly diminished transpiration rate $(\mathrm{E})$, which is more strongly affected in plants of $\mathrm{Kn.307} \mathrm{(67 \% )} \mathrm{than} \mathrm{in} \mathrm{those} \mathrm{of} \mathrm{P9528} \mathrm{(39 \% ).} \mathrm{The} \mathrm{changes} \mathrm{in} \mathrm{stomata} \mathrm{conductance}\left(\mathrm{g}_{\mathrm{s}}\right)$ of the chilled plants showed a similar trend. It was more retarded in Kn.307 than in P9528, by $80 \%$ and 50\%, respectively.

Our results confirm the negative impact of low temperatures on leaf gas exchange (Al-Shoaibi, 2008; Aroca et al., 2001) as well as the existence of different sensitivity among maize hybrids to chilling, observed in many studies (Aroca et al., 2001; Bilska and Sowinski, 2010;). The significant decrease of both $\mathrm{E}$ and $\mathrm{g}_{\mathrm{s}}$ in the chilled plants was a result of a developed leaf water deficit. Based on our previous results, we may propose that this effect was at least partly due to a chilling-induced decrease of the root mass formation (Cholakova and Vassilev, 2015).

Usually, the lower stomata conductance leads to decrease of $\mathrm{CO}_{2}$ intake in leaves and subsequently to stomata limitation of $\mathrm{CO}_{2}$ assimilation. In our experimental conditions, the internal leaf $\mathrm{CO}_{2}$ concentration $\left(\mathrm{c}_{\mathrm{i}}\right)$ of the chilled plants from both hybrids increased, which indicates that mesophyll limitations prevail over stomatal ones. The yellowing of the middle to lower part of the leaf lamina of the chilled plants motivated performing analyses on photosynthetic pigments content and photochemical efficiency.

The influence of chilling on photosynthetic pigments content is presented in Table 2 . The data shows a significant decrease in chlorophyll $(a+b)$ content in the chilled plants, being lower than in the no 
chilled controls by $46 \%$ in the plants from Kn.307 and by $21 \%$ in those from P9528. The chilling stress affected to a smaller degree the total carotenoids content. It was diminished by $24 \%$ in the plants from Kn.307 and slightly (by 4\%) and insignificantly in those from P9528.

Table 1: Influence of chilling on leaf gas exchange of young maize plants from hybrids Kn.307 and P9528. A - net photosynthetic rate $\left(\mu \mathrm{mol} \mathrm{CO}_{2} \mathrm{~m}^{-2} \mathrm{~s}^{-1}\right) ; \mathrm{E}$ - transpiration rate $\left(\mathrm{mmol} \mathrm{H}_{2} \mathrm{O} \mathrm{m}^{-2} \mathrm{~s}^{-1}\right)$, $\mathrm{g}_{\mathrm{s}}-$ stomatal conductance $\left(\mathrm{mol} \mathrm{m} \mathrm{m}^{-2} \mathrm{~s}^{-1}\right)$ and $\mathrm{c}_{\mathrm{i}}$ - internal $\mathrm{CO}_{2}$ concentration (vpm).

\begin{tabular}{|c|c|c|c|c|c|}
\hline \multirow{2}{*}{ Hybrids } & Temperature regime, ${ }^{\circ} \mathrm{C}$ & \multicolumn{4}{|c|}{ Leaf gas exchange parameters } \\
\cline { 3 - 6 } & & $\mathrm{A}$ & $\mathrm{E}$ & $\mathrm{g}_{\mathrm{s}}$ & $\mathrm{c}_{\mathrm{i}}$ \\
\hline \multirow{2}{*}{ Kn.307 } & $25 / 20$ & $16.69 \pm 0.11^{\mathrm{a}}$ & $0.71 \pm 0.04^{\mathrm{b}}$ & $0.05 \pm 0.01^{\mathrm{b}}$ & $121 \pm 6^{\mathrm{b}}$ \\
\cline { 2 - 6 } & $10 / 10$ & $5.43 \pm 0.01^{\mathrm{c}}$ & $0.24 \pm 0.08^{\mathrm{c}}$ & $0.01 \pm 0.00^{\mathrm{c}}$ & $168 \pm 2^{\mathrm{a}}$ \\
\hline \multirow{2}{*}{ P9528 } & $25 / 20$ & $18.09 \pm 0.10^{\mathrm{a}}$ & $1.08 \pm 0.07^{\mathrm{a}}$ & $0.08 \pm 0.01^{\mathrm{a}}$ & $61 \pm 8^{\mathrm{d}}$ \\
\cline { 2 - 6 } & $10 / 10$ & $10.07 \pm 0.15^{\mathrm{b}}$ & $0.66 \pm 0.09^{\mathrm{b}}$ & $0.04 \pm 0.01^{\mathrm{b}}$ & $90 \pm 9^{\mathrm{c}}$ \\
\hline
\end{tabular}

Data presented are means \pm SD. Different letters $(a, b, c$ and $d$ ) following the mean values within a column indicate significant differences at $\mathrm{P}<0.05$.

Source: Authors

The detected changes in both chlorophyll and carotenoids content resulted in a change in their ratio. The Car / Chl (a+b) ratio increased by $38 \%$ and 22\% in Kn.307 and P952, respectively. The chlorotic symptoms and enhanced leaf lipid peroxidation in maize plants are consequences of chlorophyll photooxidative damage as was shown by Leipner et al. (2009). In addition to lower chlorophyll content, the increased Car / Chl $(\mathrm{a}+\mathrm{b})$ ratio could be related to the essential function of carotenoids in protecting the photosynthetic apparatus against photo-oxidative damage. Haldiman (1998) considered increased ratio carotenoids/chlorophyll in chilling-exposed maize plants as their adaptation strategy allowing them both to reduce light absorption as well as to increase the capacity for photoprotection.

Table 2: Influence of chilling on photosynthetic pigments content $\left(\mathrm{mg} \mathrm{g} \mathrm{FW}^{-1}\right)$ and ratio in leaves of young maize plants from hybrids Kn.307 and P9528.

\begin{tabular}{|c|c|c|c|c|c|c|}
\hline Hybrids & \multirow{2}{*}{$\begin{array}{c}\text { Temperature } \\
\text { regime, }{ }^{\circ} \mathrm{C}\end{array}$} & \multicolumn{5}{|c|}{ Photosynthetic pigments content and ratio } \\
\cline { 3 - 7 } & & Chl a & Chl b & Car & Chl (a+b) & $\begin{array}{c}\text { Car / Chl } \\
(\mathrm{a}+\mathrm{b})\end{array}$ \\
\hline Kn.307 & $25 / 20$ & $3.12 \pm 0.29^{\mathrm{a}}$ & $1.00 \pm 0.08^{\mathrm{a}}$ & $0.85 \pm 0.06^{\mathrm{a}}$ & $4.12 \pm 0.12^{\mathrm{a}}$ & $0.21 \pm 0.01^{\mathrm{b}}$ \\
\cline { 2 - 7 } & $10 / 10$ & $1.76 \pm 0.04^{\mathrm{d}}$ & $0.48 \pm 0.05^{\mathrm{d}}$ & $0.65 \pm 0.05^{\mathrm{c}}$ & $2.24 \pm 0.07^{\mathrm{c}}$ & $0.29 \pm 0.03^{\mathrm{a}}$ \\
\hline P9528 & $25 / 20$ & $2.35 \pm 0.19^{\mathrm{b}}$ & $0.87 \pm 0.08^{\mathrm{b}}$ & $0.73 \pm 0.09^{\mathrm{b}}$ & $3.22 \pm 0.07^{\mathrm{b}}$ & $0.23 \pm 0.01^{\mathrm{b}}$ \\
\cline { 2 - 7 } & $10 / 10$ & $1.94 \pm 0.10^{\mathrm{c}}$ & $0.59 \pm 0.07^{\mathrm{c}}$ & $0.70 \pm 0.12^{\mathrm{b}}$ & $2.53 \pm 0.14^{\mathrm{c}}$ & $0.28 \pm 0.02^{\mathrm{a}}$ \\
\hline
\end{tabular}

Data presented are means \pm SD. Different letters (a, b, c and d) following the mean values within a column indicate significant differences at $\mathrm{P}<0.05$.

Source: Authors

The data obtained from the performed chlorophyll fluorescence analysis is presented in Table 3 . The values of all parameters achieved in the top leaf zone of both no chilled and chilled plants were almost similar (data were not shown), while significant differences were detected in the respective values measured in middle-low part zones. The maximal quantum yield of PSII $\left(\mathrm{F}_{\mathrm{v}} / \mathrm{F}_{\mathrm{m}}\right)$ of no chilled plants was the norm characteristic for healthy plants - 0.75-0.83 (Bolhar-Nordenkampf and Oquist, 1993), while the value of this parameter was significantly diminished in the chilled plants - by $15 \%$ in Kn.307 and $8 \%$ in P9528.

The reduction is due to both an increase of minimal fluorescence $\left(\mathrm{F}_{0}\right)$ and decreases in the maximal one $\left(\mathrm{F}_{\mathrm{m}}\right)$. While an increase of $\mathrm{F}_{0}$ usually points to photodamage, a reduction of $\mathrm{F}_{\mathrm{m}}$ reflects heat dissipation as a mechanism for photoprotection (Schreiber, 2004). The lower $F_{v} / F_{m}$ in the chlorotic leaf 
zones of chilled plants is a marker of photoinhibition (Bilska and Sowinski, 2010; Kosova et al., 2005). Another reason for this effect could be impaired chloroplast development as suggested by Nie at al. (1995). Considering the absence of significant changes in the $F_{v} / F_{m}$ value in the top "healthy" leaf zones, we assume that the major limiting factor could be disturbed chloroplast development in the chlorotic ones. Nie et al. (1995) showed that several chloroplast polypeptides, including the very important for PSII functioning - D1, are poorly expressed in Zea mays leaves grown at chilling temperatures.

The apparent electron transport rate (ETR) is a calculated parameter representing linear electron transport rate of the overall in vivo photosynthetic process. In the chilled maize plants, it was retarded by $44 \%$ and $26 \%$ in $\mathrm{Kn} .307$ and P9528, respectively. Using the so-called "quenching analysis" it is possible to distinguish the use of absorbed light for photochemical conversion and non-photochemical loss of excitation energy (Schreiber, 2004). Photochemical quenching (qP) indicates the proportion of open PSII reactive centers, while non-photochemical quenching $(\mathrm{qN})$ - heat dissipation. The results presented in Table 3 show that the applied chilling treatment decreased very slightly (by 5-6\%), but significantly, the $\mathrm{qP}$ values and sharply increased the qN values - by $97 \%$ in $\mathrm{Kn} .307$ and $72 \%$ in P9528. The obtained fluorescence data demonstrate that the photochemical efficiency of the chilled maize plants was lowered. A small part of the reaction centers in PSII was closed. Due to the decrease in $\mathrm{CO}_{2}$ assimilation, the absorbed excitation energy overloaded the electron-transport processes. Therefore, the "excess" light was sufficiently de-excitated by heat dissipation. Similarly to the other observed changes in the photosynthetic parameters, the chilling effect on chlorophyll fluorescence was higher in plants from in Kn.307 than in P9528.

Table 3: Influence of chilling on selected chlorophyll fluorescence parameters in young maize plants from hybrids Kn.307 and P9528. $F_{0}-$ minimal level of fluorescence; $F_{m}-$ maximal level of fluorescence; $F_{v} / F_{m}-$ maximal quantum yield of PSII; ETR - apparent electron transport rate; $\mathrm{qP}$ - photochemical quenching; $\mathrm{qN}$ non-photochemical quenching.

\begin{tabular}{|l|c|c|c|c|c|c|c|}
\hline Hybrids & \multirow{2}{*}{$\begin{array}{c}\text { Temperature } \\
\text { regime, }\end{array}$} & \multicolumn{6}{|c|}{$\mathrm{C}$} \\
\cline { 3 - 8 } & & $\mathrm{F}_{0}$ & $\mathrm{~F}_{\mathrm{m}}$ & $\mathrm{F}_{\mathrm{v}} / \mathrm{F}_{\mathrm{m}}$ & ETR & $\mathrm{qP}$ & $\mathrm{qN}$ \\
\hline Kn.307 & $25 / 20$ & $209 \pm 10^{\mathrm{c}}$ & $932 \pm 15^{\mathrm{b}}$ & $0.78 \pm 0.03^{\mathrm{a}}$ & $42.2 \pm 3.2^{\mathrm{a}}$ & $0.477 \pm 0.11^{\mathrm{a}}$ & $0.293 \pm 0.15^{\mathrm{c}}$ \\
\cline { 2 - 8 } & $10 / 10$ & $253 \pm 6^{\mathrm{a}}$ & $736 \pm 21^{\mathrm{c}}$ & $0.66 \pm 0.02^{\mathrm{c}}$ & $23.8 \pm 5.1^{\mathrm{b}}$ & $0.446 \pm 0.06^{\mathrm{b}}$ & $0.577 \pm 0.10^{\mathrm{a}}$ \\
\hline P9528 & $25 / 20$ & $238 \pm 8^{\mathrm{b}}$ & $1091 \pm 32^{\mathrm{a}}$ & $0.78 \pm 0.03^{\mathrm{a}}$ & $38.1 \pm 3.0^{\mathrm{a}}$ & $0.420 \pm 0.20^{\mathrm{c}}$ & $0.241 \pm 0.08^{\mathrm{d}}$ \\
\cline { 2 - 8 } & $25 / 20$ & $251 \pm 2^{\mathrm{a}}$ & $902 \pm 24^{\mathrm{b}}$ & $0.72 \pm 0.01^{\mathrm{b}}$ & $28.3 \pm 4.2^{\mathrm{b}}$ & $0.397 \pm 0.14^{\mathrm{c}}$ & $0.415 \pm 0.12^{\mathrm{b}}$ \\
\hline
\end{tabular}

Data presented are means \pm SD. Different letters ( $a, b, c$ and $d$ ) following the mean values within a column indicate significant differences at $\mathrm{P}<0.05$.

Source: Authors

\section{Conclusion}

The young maize plants from the hybrids Kn.307 and P9528 suffered from chilling stress when exposed for seven days at $10{ }^{\circ} \mathrm{C}$. They responded to this treatment by different physiological alterations, including growth retardation, increased membrane lipids peroxidation, diminished leaf gas exchange, decreased photosynthetic pigments and lowered efficiency of PSII photochemistry. These alterations were more pronounced in the chilling-exposed plants of the hybrid Kn.307 than in those of P9528. Based on the obtained results we consider the hybrid P9528 as more tolerant to chilling at the early stage of plant development. Further studies will be performed to evaluate its tolerance in field conditions as well as to describe the physiological bases for this important trait. 


\section{References}

Al-Shoaibi, A.A. (2008). Photosynthetic response to the low temperature in Elephant Grass (Peninsetum purpureum) and Zea mays., International journal of Botany, 4 (3), 309-314.

Aroca, R., Irigoyen, J.J., \& Sánchez-Díaz, M. (2001). Photosynthetic characteristics and protective mechanisms against oxidative stress during chilling and subsequent recovery in two maize varieties differing in chilling sensitivity. Plant Sci 161: 719-726.

Aroca, R., Irigoyen, J.J., \& Sánchez-Díaz, M. (2003). Drought enhances maize chilling tolerance. II. Photosynthetic traitsand protective mechanisms against oxidative stress. Pysiologia Plantarum 117: 540-549.

Bano, S., Aslam, M., Saleem, M., Basra, S.M.A., \& Aziz, K. (2015). Evaluation of maize accessions under low temperature stress at early growth stages. J. Anim. Plant Sci. 25:392-400.

Bilska, A., \& Sowiński, P. (2010). Closure of plasmodesmata in maize (Zea mays) at low temperature: a new mechanism for inhibition of photosynthesis. Ann. Bot. Nov; 106(5): 675-686.

Bolhar-Nordenkampf, H.R., \& Oquist, G. (1993). Chlorophyll fluorescence as a tool in photosynthesis research. In: Photosynthesi and production in a changing environment: a field and laboratory manual (Eds. D. O. Hall, J. M. O. Scurlock, h. R. Bolnar-Nordenkampf, R. C. Leegood, S. P. Long). Chapman and Hall, London, 193-205.

Cholakova-Bimbalova, R., \& Vassilev, A. (2015). Influence of low temperatures on the growth and macronutrient content in young maize plants. Scientific Works of Agricultural University - Plovdiv, vol. LIX, book 2, 87 - 94.

Farooq, M., Aziz, T., Basra, S.M.A., Cheema, M.A., \& Rehamn, H. (2008). Chilling tolerance in hybrid maize induced by seed priming with salicylic acid. Journal of Agronomy and Crop Science 194: 161-. 168.

Foyer, C.H., Vanacker, H., Gomez, L.D., Harbinson, J. (2002). Regulation of photosynthesis and antioxidant metabolism in maize leaves at optimal and chilling temperatures: review. Plant Physiology and Biochemistry 40: 659-668.

Genty, B., Briantais, J.M., \& Baker, N.R. (1989). The relationship between the quantum yield of photosynthetic electron transport and quenching of chlorophyll fluorescence. Biochim Biophys Acta 990:87-92.

Haldimann, P. (1998). Low growth temperature-induced changes to pigment composition and photosynthesis in Zea mays genotypes differing in chilling sensitivity. Plant, Cell and Environment, 21, 200-208.

Haldimann, P. (1999). How do changes in temperature during growth affect leaf pigment composition and photosynthesis in Zea mays genotypes differing in sensitivity to low temperature? Journal of Experimental Botany, Vol. 50, No. 333, pp. 543550 .

Heath, R.L., \& Packer, L. (1968). Photoperoxidation in isolated chloroplasts. I. Kinetics and stoichiometry of fatty acid peroxidation, Arch. Biochem. Biophys. 125, 189- 198.

Hola D, Kocova M, Rothova O, Wilhelmova N, Benesova M. 2007. Recovery of maize (Zea mays L.) inbreds and hybrids from chilling stress of various duration: photosynthesis and antioxidant enzymes. Journal of Plant Physiology 164, 868-877. Kosová, K., Haisel, D., Tichá, I. (2005). Photosynthetic performance of two maize genotypesas affected by chilling stress Leipner, J., \& Stamp, P. (2009). Chilling stress in maize seedlings. In: Bennetzen, J.L., Hake, S.C. (eds) Handbook of Maize: Its Biology, pp. 291-310. Springer, Heidelberg.

Lichtenthaler, H.K. (1987). Chlorophylls and carotenoids: pigments of photosynthetic biomembrans. Methods enzymol., 148, 350-382.

Melkonian, J., Long-Xi, Y., \& Setter T.L. (2004). Chilling responses of maize (Zea mays L.) seedlings root hydraulic conductance, abscisic acid, and stomatal conductance Journal of Experimental Botany, Vol. 55, No. 403, pp. 1751-1760, August 2004.

Miedema, P. (1982). The effects of low temperature on Zea mays L. Advances in Agronomy 35: 93-129.

Moseki, M. (2004). Characterisation of low temperature stress effects on photosynthetic performance of maize cultivars using chlorophyll fluorescence., South African Journal of Botany Volume 70, Issue 5, December 2004, Pages 730-733.

Nie, G.Y., Long, S.P., \& Baker, N.R. (1992). The effects of development at sub-optimal growth temperatures on photosynthetic capacity and susceptibility to chilling-dependent photoinhibition in Zea mays. Physiol Plant 85: 554-560.

Nie, G.Y., Robertson, E.J., Fryer, M.J., Leech, R.M., \& Baker, N.R. (1995). Response of the photosynthetic apparatus in maize leaves grown at low temperature on transfer to normal growth temperature. Plant, Cell and Environment 18, 1-12. Plant Soil Environ., 51, 2005 (5): 206-212.

Schreiber, U. (2004). Pulse amplitude modulation (PAM) fluorometry and saturation pulse method: an overview. Papageorgiou, G. C. (ed). In Chlorophyll a fluorescence: a signature of photosynthesis Dordrecht: Kluwer Academic. pp. 279-319.

Sowinski, P., Rudzinska-Langwald, A., Adamczyk, J., Kubica, I., \& Fronk, J. (2005). Recovery of maize seedlings growth, developmentand photosynthetic efficiency after initial growth at low temperature. J Plant Physiol., 162:67-80.

Stamp, P. (1984). Chilling tolerance of young plants demonstrated on the example of maize (Zea mays L.), J. Agron. Crop Sci. 7 1-83.

Takáč, T. (2004). The relationship of antioxidant enzymesand some physiological parameters in maize during chilling Plant Soil Environ., 50, (1): 27-32

Zaidi, P.H., Yadav, M., Maniselvan, P., Khan, R., Shadakshari, T.V., Singh, R.P., \& Pal, D. (2010). Morpho-physiological traits associated with cold stress tolerance in tropical maize (Zea mays L.). Maydica. 55: 201-208. 